\title{
The Process Category Selection Model and Application of Silicon Rod Slicing Based on Green Manufacturing
}

\author{
Wu Chaohua \\ School of Mechanical and Electrical Engineering \\ Wuhan University of Technology \\ Wuhan, China; \\ e-mail: wuchaohuavip@163.com
}

\author{
Chen Lei \\ School of Mechanical and Electrical Engineering \\ Wuhan University of Technology \\ Wuhan, China; \\ e-mail: chenlei811001@163.com \\ Corresponding Author
}

\begin{abstract}
The development of cutting technology of hard and brittle material went through cylindrical cutting and internal cutting,free mortar multi-line cutting and diamond multi-line cutting.At present the main processing method of solar grade silicon rod slicing is free mortar multi-line cutting and diamond multi-line cutting.The paper establishes a production target model for silicon rod slicing based on green manufacturing,cites 6 index of main parameters of free mortar multi-line cutting and diamond multi-line cutting for quality $(Q)$, time $(T)$, cost $(C)$, environment protection (E), consumption of $\operatorname{resources}(\mathrm{R})$ and HMI properties $(\mathbf{H})$ when cutting polycrystalline silicon 156.In order to select the best process category for silicon rod slicing based on green manufacturing, The paper attempts to study process category selection of Silicon Rod Slicing as a research object and adopts the analytic hierarchy process (AHP) and the fuzzy comprehensive evaluation method to calculate and assess. The results shows that diamond multiwire cutting is better than free mortar multi-line cutting on green manufacturing process planning.
\end{abstract}

Keywords-Diamond Wire Cutting;Green Manufacturing; Process category selection;free mortar multi-line cutting;fuzzy comprehensive evaluation

\section{INTRODUCTION}

Silicon rod is the main production materials for semiconductor and photovoltaic field. In recent years, with the rapid development of silicon materials and sapphire material applications, the equipment and technology for cutting hard and brittle materials are constantly updated.At present the main cutting methods include cylindrical cutting,internal cutting,free mortar multi-line cutting and diamond multi-line cutting and so on.

Cylindrical cutting technology appeared in the 19th century in Europe.The cutting speed is affected by vibration and noises are quite serious. Rotating at high speed, the noise even more than $110 \mathrm{db}$. Noises not only pollute the environment but also reduce the cutting precision, When using cylindrical cutter, the surface quality of silicon wafer is not high, and the efficiency is low.

Cutting widely used in the inner circle cut glass, sapphire, silicon rods and other hard and brittle materials with high stability and high material utilization. When slicing $200 \mu \mathrm{m}$ or less single-crystal silicon,it will have a greater warpage.

\begin{abstract}
Cylindrical cutting and internal cutting is very limited for silicon rod slicing with low cutting efficiency.Internal cutting is only used when prescribing silicon rods.At present the main processing method of solar grade silicon rod slicing is free mortar multi-line cutting and diamond multi-line cutting.
\end{abstract}

\section{Multi-WiRe CutTing TeChNOLOGY}

Multi-wire cutting technology for silicon rod slicing is currently the most advanced technology for silicon rod slicing.Its principle is drive the cutting edge in the attached wire on the material of friction on the silicon rod through the steel wire' $s$ high-speed movement, so as to achieve the cutting effect. Silicon rod to be machined will be sliced through the decline of the table feed.Multi-wire cutting technology has the advantages of high efficiency, high productivity, high precision, including free mortar multiline cutting and diamond multi-line cutting[1].

Under the effect of the mortar free mortar multi-line cutting complete the slicing process through a multi-line high-speed reciprocating movement of the wire.Due to free mortar mixed in some diamond particles, it has the advantages of high production efficiency, low material loss and high surface quality.The diamond particles may cause surface crackle,residual stress and deeper phase change layer.After slicing the residual stress can cause warpage of the wafer itself, which require subsequent processing trimmed.Precision of the machined surface is not easy to control.

Diamond multi-wire cutting consolidates $\mathrm{SiC}$ particles in the steel line.Using the principle of cutting the abrasive particles and silicon rods.Abrasive particles directly cut silicon rods.It belongs to a rigid cutting method.Cutting system can be employed a low viscosity coolant or aqueous lubricating fluid.Recovering chips is easier. Energy saving and environmental protection is very obvious.However, diamond multi-line cutting equipment is more expensive.Mechanical properties of steel wire is greatly demanded.

\section{ANALYTIC HIERARCHY PROCESS (AHP)}

AHP is a simple, flexible and practical method for multi-objective decision by American operations research experts A.L.Satty in the 1970s.Its basic idea is the total 
goal will be decomposed into several sub goal evaluation, then the sub target calculates the relative weight according to evaluation aspects of evaluation.Finally, the total objective comparison, comparative data from the final decision can often be an optimal solution, meet the set target.

\section{A. Constructing Model}

It will be a predetermined target as the goal layer, achieve the goal of each evaluation as part of the criterion layer, the lowest layer is the plan layer, which is showed in Fig .1[2][3].

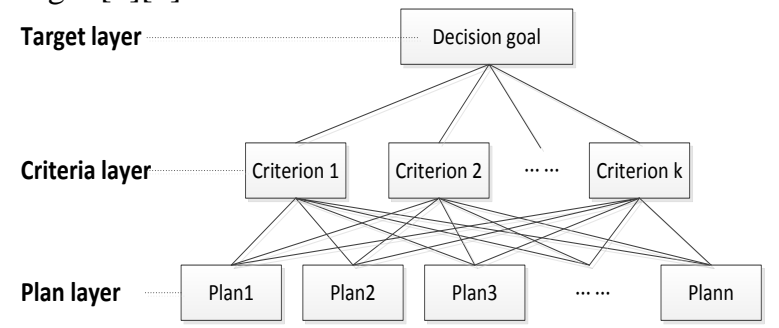

Figure 1. The hierarchical structure of AHP

\section{B. Establishing Judgment Matrix}

After the establishment of the hierarchy model, subordinate relationship between target layer, criteria layer and plan layer element has been determined, for easy comparison of each factor under a layer and a layer of selected relatively important degree.The evaluation index of relative importance degree judgment scale indicated by 1-9 is showed in Table I.

TABLE I. THE EVALUATION INDEX OF RELATIVE IMPORTANCE DEGREE JUDGMENT SCALE

\begin{tabular}{|c|c|}
\hline Judgement Scales & Meaning (Representation for A) \\
\hline 1 & $\begin{array}{c}\text { Comparison of factor } B_{i} \text { and factor }{ }_{j}, B_{i} \text { and } \\
B_{j} \text { are equally important }\end{array}$ \\
\hline 3 & $\begin{array}{c}\text { Comparison of factor }{ }^{B_{i}} \text { and factor } \\
\text { slightly important }\end{array}$ \\
\hline 5 & $\begin{array}{c}B_{j} B_{i} \text { is } \\
\text { obviously important }\end{array}$ \\
\hline 7 & Comparison of factor $B_{i}$ and factor ${ }^{B_{j}}, B_{i}$ is \\
\hline 9 & $\begin{array}{c}\text { important } \\
\text { Comparison of factor }{ }^{B_{i}} \text { and factor } \\
\text { absolutely important }\end{array}$ \\
\hline$B_{j}, B_{i}$ is \\
\hline $2,4,6,8$ & Between two adjacent judgment scale \\
\hline
\end{tabular}

$\mathrm{b}_{i j}$ in the Judgment matrix refers to the degree of importance of indicator 1 relative to 2 . That is

$$
b_{i j}=\frac{W_{i}}{W_{j}}
$$

From the above equation

$$
\begin{gathered}
b_{i i}=1 \\
b_{i j}=\frac{1}{b_{i j}}(i, j=1,2,3, \mathrm{~K}, n)
\end{gathered}
$$

Through the above comparison, we can get the judgment matrix.To ensure the objectivity of comparative data, $b_{i j}$ is based on data, expert opinions and analysts awareness.

\section{Single level criteria ranking and consistency inspection}

Single criteria ranking refers to the calculation of relative weights of criteria for a next element according to the judgment matrix,For each element of the criterion layer, a weight vector $W=\left(w_{1}, w_{2}, w_{3}, \mathrm{~K}, w_{i}, \mathrm{~K}, w_{n}\right)^{T}$,Obtained by solving the following equation.

$$
A W=\lambda_{\max } W
$$

In the formula, $\lambda_{\max }$ is the largest eigenvalue of the judgement matrix A.W is the normalized eigenvector corresponding to the $\lambda_{\max }$.Component of $\mathrm{W}, w_{i}$ is the corresponding weight value of single sort elements.

If the judgment matrix $\mathrm{B}$ has the complete consistency, $\lambda_{\max }=$ n.However, in general it is not necessarily consistent.In order to test the consistency of judgment matrix, we need to compute the consistency index.

$$
C I=\frac{\lambda_{\max }-n}{n-1}
$$

When $\mathrm{CI}=0$,judgment matrix is completely consistent.The greater the CI, the consistency of the judgment matrix is worse.In order to test whether the judgment matrix with satisfactory consistency, we need to compare CI with RI(The average random consistency index).

In general, the judgment matrix of 1 or 2 order is always with complete consistency.For the judgment matrices of order 2 or more, ratio of the consistency index CI with the same order of mean random consistency index RI (Table II), called the stochastic judgment matrix consistency ratio, denoted as CR.

$$
\text { When } C R=\frac{C I}{R I}<0.10 \text {,The judgment matrix is consistency }
$$
with satisfactory. Otherwise, when $C R \geq 0.10$,it need to adjust the judgment matrix until satisfied.

TABLE II. THE EVALUATION INDEX OF THE AVERAGE RANDOM CONSISTENCY INDEX RI VALUE

\begin{tabular}{|c|c|c|c|c|c|c|c|c|c|c|c|c|}
\hline $\begin{array}{c}\text { Order } \\
\text { Number }\end{array}$ & 1 & 2 & 3 & 4 & 5 & 6 & 7 & 8 & 9 & 10 & 11 & 12 \\
\hline RI & 0 & 0 & 0.58 & 0.9 & 1.12 & 1.24 & 1.32 & 1.41 & 1.45 & 1.49 & 1.52 & 1.54 \\
\hline
\end{tabular}

\section{TARGET MODEL BASED ON GREEN MANUFACTURING}

Green manufacturing, also called environmental conscious manufacturing or manufacturing for environment,is a comprehensive modern manufacturing mode of consideration environmental impacts and resource efficient[4][5].Goal is to make green manufacturing product design, manufacturing, packaging, transportation, use to scrap the entire product life cycle, environmental impact (negative effect) Minimum, maximum utilization of resources, and economic and social benefits coordination optimization.

How to choose the type of slicing need to consider goal systems of green manufacturing.According to "Green Mechanical Products Manufacturing Process Planning" 
(GB / $\mathrm{T}$ 28613-2012), green manufacturing process planning objective is to meet the product quality, production costs, production efficiency based on minimizing resource consumption, lower production process ecological impact and human health and safety risks. By green manufacturing process planning, it aims to achieve the following six objectives of coordination and optimization[6][7].

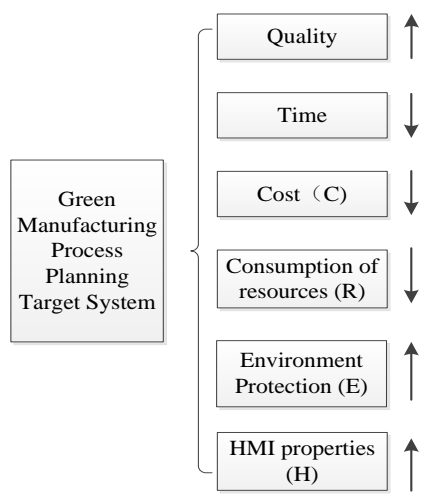

Figure 2. Green Manufacturing Process Planning Target System

\section{TARGET SYSTEM AND PARAMETERS OF PROCESS CATEGORY SELECTION}

The paper attempts to study process category selection of Silicon Rod Slicing as a research object,and compares processing parameters on quality, time, cost, consumption of resources, environment protection and HMI properties of free mortar multi-line cutting and diamond multi-line cutting.

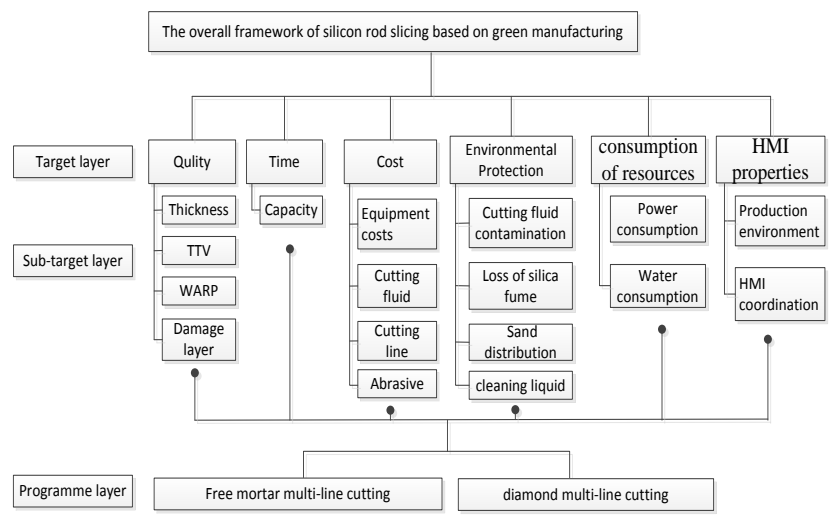

Figure 3. The overall framework of silicon rod slicing based on green manufacturing

When slicing Monocrystalline 156,Comparison of free mortar multi-line cutting and diamond multi-line cutting,Process parameters of the overall framework of silicon rod slicing based on green manufacturing are listed in the table III below.

If you are considering the quality $(\mathrm{Q})$, time $(\mathrm{T})$, cost (C), environment protection (E), consumption of resources $(\mathrm{R})$ and HMI properties $(\mathrm{H})$ to comprehensive evaluation and decision-making, it is necessary to establish a multi-objective decision-making model and choose decision-making methods for finding the optimal solution.
TABLE III. PROCESS PARAMETERS OF THE OVERALL FRAMEWORK OF SILICON ROD SLICING

\begin{tabular}{|c|c|c|c|}
\hline Project & Main parameters & $\begin{array}{c}\text { Free mortar } \\
\text { multi-line } \\
\text { cutting }\end{array}$ & $\begin{array}{l}\text { Diamond multi- } \\
\text { line cutting }\end{array}$ \\
\hline \multirow{4}{*}{ Quality } & Thickness $(\mu \mathrm{m})$ & $200 \pm 20$ & $180+10$ \\
\hline & $\operatorname{TTV}(\mu \mathrm{m})$ & $\leqslant 30$ & $\leqslant 10$ \\
\hline & $\mathrm{WARP}(\mu \mathrm{m})$ & $\leqslant 50$ & $\leqslant 30$ \\
\hline & Damage layer $(\mu \mathrm{m})$ & $\leqslant 30$ & $\leqslant 10$ \\
\hline \multirow{2}{*}{ Time } & $\begin{array}{l}\text { Cutting speed } \\
(\mathrm{mm} / \mathrm{min})\end{array}$ & 0.33 & 0.83 \\
\hline & $\begin{array}{l}\text { Capacity (piece/ } \\
\text { Month,6.5) }\end{array}$ & 187200 & 386400 \\
\hline \multirow{4}{*}{ Cost } & $\begin{array}{l}\text { Equipment costs (One } \\
\text { million / units) }\end{array}$ & $\begin{array}{l}\text { The more } \\
\text { expensive } \\
\text { (About400) }\end{array}$ & $\begin{array}{c}\text { The most } \\
\text { expensive } \\
\text { (About700) }\end{array}$ \\
\hline & Cutting fluid & $\begin{array}{l}\text { PEG cutting } \\
\text { fluid }\end{array}$ & $\begin{array}{l}\text { Water soluble } \\
\text { cutting fluid }\end{array}$ \\
\hline & Cutting line & Steel wire & Diamond wire \\
\hline & Abrasive & $\begin{array}{c}\text { Silicon carbide } \\
\text { powder }\end{array}$ & No \\
\hline \multirow{4}{*}{$\begin{array}{c}\text { Environm } \\
\text { ent } \\
\text { protection }\end{array}$} & Sand distribution & $\begin{array}{c}\text { Powder } \\
\text { contamination }\end{array}$ & No \\
\hline & $\begin{array}{l}\text { Cutting fluid } \\
\text { contamination }\end{array}$ & $\begin{array}{c}\text { PEG cutting } \\
\text { fluid }\end{array}$ & $\begin{array}{l}\text { Water soluble } \\
\text { cutting fluid }\end{array}$ \\
\hline & Loss of silica fume & Scrap & $\begin{array}{l}\text { The use of } \\
\text { recovery }\end{array}$ \\
\hline & Cleaning liquid & Need & The basic need \\
\hline \multirow{3}{*}{$\begin{array}{c}\text { Consumpt } \\
\text { ion of } \\
\text { resources }\end{array}$} & Rated power ( KW) & 140 & 140 \\
\hline & $\begin{array}{c}\text { Power } \\
\text { consumption(KW/piece })\end{array}$ & 0.356 & 0.1157 \\
\hline & $\begin{array}{l}\text { Water consumption } \\
\text { (M3/piece) }\end{array}$ & 0.0075 & 0.0021 \\
\hline \multirow{2}{*}{$\begin{array}{c}\text { HMI } \\
\text { properties }\end{array}$} & $\begin{array}{l}\text { The health of human } \\
\text { body }\end{array}$ & Smaller & Smaller \\
\hline & Safety Hazards & The general & Smaller \\
\hline
\end{tabular}

\section{GReEN MANUfACTURING PROCESS CATEGORY} SELECTION ALGORITHM

It is necessary to consider QTCERH properties of the target based on green manufacturing When selecting process category of silicon rod slicing, therefore, which is multi-objective decision-making. The commonly used method of multi-object decision making is fuzzy comprehensive evaluation method and AHP.In this paper, fuzzy comprehensive evaluation method is used to To solve the problem of selection process category of silicon rod slicing

Fuzzy comprehensive evaluation steps:

Step1:Establishing the factors set[8][9]

Factor, also known as parameter indicators or quality indicators,reflect the quality of the object.The factor set is a common set of a variety of factors influencing the evaluation object. $\mathrm{U}=\left\{\mathrm{u} 1, \mathrm{u} 2, \mathrm{u} 3, \ldots, \mathrm{u}_{\mathrm{n}}\right\}$.

- Step2:Establishing the evaluation set

Membership refers to the subject of more than one judge to make a judgment object $u_{i}$ and $v_{j}$ assessed in terms of likelihood. $\mathrm{V}=\left\{\mathrm{v}_{1}, \mathrm{v}_{2}, \mathrm{v}_{3}, \ldots, \mathrm{v}_{\mathrm{m}}\right\} . \mathrm{V}_{\mathrm{j}}$ is representative of various possible evaluation results. 
- Step3:Determining univariate judgment membership vector and forming a membership matrix.

Membership refers to probability of multiple evaluation body to make the $\mathrm{v}_{\mathrm{j}}$ assessment in $\mathrm{u}_{\mathrm{i}}$ for a judgment object.Vector membership of evaluation factors i is $R_{i}$.

$$
\underset{\sim}{R_{i}}=\left(\mathrm{r}_{\mathrm{i} 1}, \mathrm{r}_{\mathrm{i} 2}, \mathrm{r}_{\mathrm{i} 3}, \ldots, \mathrm{r}_{\mathrm{im}}\right), \mathrm{i}=1,2,3, \ldots, \mathrm{n}, \sum_{j=1}^{m} r_{i j}=1
$$

Membership matrix

Therefore,

$$
\underset{\sim}{R}=\left(R_{1}, R_{2}, R_{3}, \Lambda, R_{n}\right)^{T}
$$

$$
\underset{\sim}{R}=\left[\begin{array}{cccc}
r_{11} & r_{12} & \Lambda & r_{1 m} \\
r_{21} & r_{22} & \Lambda & r_{2 m} \\
\mathrm{M} & \mathrm{M} & \mathrm{M} & \mathrm{M} \\
r_{n 1} & r_{n 2} & \Lambda & r_{n m}
\end{array}\right]
$$

- Step4:Establishing factor weights set

Among the factors, the importance of each factor is not the same. In order to reflect the importance of various factors, factors that should be given to a certain weight, set by the weighting factor called factor composed of weight set.

$$
\underset{\sim}{W}=\left\{\mathrm{w}_{1}, \mathrm{w}_{2}, \mathrm{w}_{3}, \ldots, \mathrm{w}_{\mathrm{n}}\right\}, \sum_{i=1}^{\mathrm{n}} w_{i}=1
$$

- Step5:The fuzzy comprehensive evaluation

According to the fuzzy algorithm to calculate a comprehensive assessment vector ${ }_{S}$ (Integrated membership vector) and a comprehensive assessment value $\mathrm{Z}$.

$$
\underset{\sim}{S}=\underset{\sim}{R} \underset{\sim}{W}, \mathrm{Z}=\mathrm{W}_{\mathrm{E}} \mathrm{S}^{\mathrm{T}}
$$

$\mathrm{W}_{\mathrm{E}}$ is the corresponding value of the reviews[10].

\section{CASE STUDY}

An enterprise wants to develop, design and produce the project of silicon rod slicing.Due to the higher requirements of green manufacturing for export products, Now you need to determine process category of silicon rod slicing based on past process data.

The first Step: To determine the evaluation factor set according to the evaluation objectives.

The evaluation factors set $U=\{$ quality, time, cost, consumption of resources, environment protection,HMI properties $\}$

The second Step: Establishing evaluation set.

The evaluation grade set $\mathrm{V}=\{$ the best, good, general, poor, very poor\}

TABLE IV. ClassificATION AND EVALUATION OF THE CORRESPONDING VALUATION

\begin{tabular}{|c|c|c|c|c|c|}
\hline degree & the best & good & general & poor & very poor \\
\hline Score & 9 & 7 & 5 & 3 & 1 \\
\hline
\end{tabular}

The third step: to determine the membership matrix

In the course of quantization and standardized evaluation,it is necessary to quality, time, cost, environment protection, consumption of resources and HMI properties according to table IV.
$R=\left[\begin{array}{lllllllllllllllllll}7 & 5 & 7 & 5 & 5 & 7 & 5 & 5 & 5 & 7 & 5 & 3 & 3 & 5 & 7 & 5 & 3 & 5 & 5 \\ 9 & 9 & 9 & 7 & 7 & 9 & 1 & 7 & 3 & 9 & 9 & 5 & 7 & 7 & 7 & 7 & 7 & 5 & 7\end{array}\right]^{T}$

The fourth step: to establish factor weight set

Set quality, time, cost, environment protection, consumption of resources and HMI properties of each factor are

$[(0.09,0.09,0.06,0.06),(0.02,0.08),(0.1,0.02,0.04,0.04),(0.0$ $5,0.05,0.05,0.05),(0.02,0.04,0.04),(0.05,0.05)]$.

That is

$\mathrm{W}=(0.09,0.09,0.06,0.06,0.02,0.08,0.1,0.02,0.04,0.04,0.05$, $0.05,0.05,0.05,0.02,0.04,0.04,0.05,0.05)$.

The fifth step: to evaluate comprehensively $S=R \mathrm{~W}=[0.09,0.09,0.06,0.06,0.02,0.08,0.1,0.02,0.04,0.04$ $, 0.05,0.05,0.05,0.05,0.02,0.04,0.04,0.05,0.05]$

$\left[\begin{array}{lllllllllllllllllll}7 & 5 & 7 & 5 & 5 & 7 & 5 & 5 & 5 & 7 & 5 & 3 & 3 & 5 & 7 & 5 & 3 & 5 & 5 \\ 9 & 9 & 9 & 7 & 7 & 9 & 1 & 7 & 3 & 9 & 9 & 5 & 7 & 7 & 7 & 7 & 7 & 5 & 7\end{array}\right]^{T}$ $=(5.3,6.86)$

\section{CONCLUSIONS}

The paper makes a decision to selection process category based on green manufacturing by fuzzy comprehensive evaluation method.The results $(5.3,6.86)$ shows that diamond multi-wire cutting is better than free mortar multi-line cutting on green manufacturing process planning.

\section{ACKNOWLEDGEMENT}

Our thanks to the research fund of China national natural Science under the grant number of 51405355.

\section{REFERENCES}

[1] Shan Zhongde and $\mathrm{Hu}$ Shihui, “Greening the traditional mechanical manufacturing process,"Mechanical industry press, 2013.

[2] Wang Jingsong,Xiang Dong and Duan Guanghong, "Introduction to Product Greening Engineering,'Tsinghua university press,2010.

[3] Liu Zhifeng, “ Green Design Method, Technique and Its Application,"National defence industry press,2008.

[4] Liu Fei,Cao huajun and Zhanghua, "Green Manufacturing Theory and Technology,"Science press,2005.

[5] Aman CHITRAKAR,Liu Fei,Cao Hua-jun and He Yan, "A model for end-of-life vehicles management based on green manufacturing,"Journal of Chongqing University,vol:5, Mar.2006, pp.1-7.

[6] Dornfeld, David, “ Green manufacturing and resiliency,”SMT Surface Mount Technology Magazine,vol:27, Oct.2012,pp.32-36.

[7] Gu Zhen yu, Cao Hua jun and Liu Fei, "Customization product green design support system based on disassembly tree model,"Computer Integrated Manufacturing Systems,vol:15, Apr. 2009,pp.640-644.

[8] Zhong Dong Jie, "Study on a green manufacturing process design system," 3rd International Conference on Advanced Design and Manufacturing Engineering(ADME 2013),Applied Mechanics and Materials,vol:397-400,2013,pp.57-61,doi:10.4028/www.scientific. net/AMM.397-400.57.

[9] Deif,Ahmed M,“A system model for green manufacturing," Journal of Cleaner Production, vol.19,Sep.2011,pp.15531559,doi:10.1016/j.jclepro.2011.05.022.

[10] Liu Hua,Chen Weiping,Kang Zhixin NGAI Tungwai and LI Yuanyuan,"Fuzzy Multiple Attribute Decision Making for Evaluating Aggregate Risk in Green Manufacturing,"Tsinghua Science and Technology,vol.10,Oct.2005,pp.627-632. 